\title{
Synthesis, Optimization, Property, Characterization, and Application of Dialdehyde Cross-Linking Guar Gum
}

\author{
Tang Hongbo, Li Yanping, Zhang Wen, and Dong Siqing \\ Science School, Shenyang University of Technology, Shenyang 110870, China \\ Correspondence should be addressed to Tang Hongbo; tanghb6666@sina.com
}

Received 28 July 2016; Accepted 3 October 2016

Academic Editor: Antje Potthast

Copyright (C) 2016 Tang Hongbo et al. This is an open access article distributed under the Creative Commons Attribution License, which permits unrestricted use, distribution, and reproduction in any medium, provided the original work is properly cited.

\begin{abstract}
Dialdehyde cross-linking guar gum (DCLGG), as a novel material, was synthesized using phosphorus oxychloride as a cross-linking reagent, sodium periodate as an oxidant, and ethanol as a solvent through keeping the original particle form of guar gum. The process parameters such as the reaction temperature, reaction time, $\mathrm{pH}$, amount of sodium periodate, and amount of ethanol were optimized by the response surface methodology in order to obtain the regression model of the oxidization. The covalent binding of L-asparagine onto the surfaces of DCLGG was further investigated. The results showed that the best technological conditions for preparing DCLGG were as follows: reaction temperature $=40^{\circ} \mathrm{C}$, reaction time $=3.0 \mathrm{~h}, \mathrm{pH}=4.0$, and amount of ethanol $=74.5 \%$. The swelling power of DCLGG was intermediate between cross-linking guar gum and dialdehyde guar gum. The cross-linking and dialdehyde oxidization reduced the viscosity of GG. The cross-liking reduced the melting enthalpy of GG. However, the oxidization increased melting enthalpy of ACLGG. The thermal stability of GG was increased by cross-linking or oxidization. The variation of the onset decomposition temperature and end decomposition temperature of GG was not consistent with thermal stability of GG. L-asparagine could be chemically bound well by DCLGG through forming Schiff base under the weak acidity. The maximum adsorption capacity of L-asparagine on DCLGG with aldehyde content of $56.2 \%$ reached $21.9 \mathrm{mg} / \mathrm{g}$.
\end{abstract}

\section{Introduction}

Guar gum (GG), which is a natural water-soluble nonionic polysaccharide isolated from the seeds of Cyamopsis tetragonolobus, is an attractive material for the controlled drug delivery. Chemically, GG belongs to the galactomannan family. It consists of $(1 \rightarrow 4)$ - $\beta$-D-mannopyranosyl units with $\alpha$-D-galactopyranosyl units attached by the $1 \rightarrow 6$ linkages. It has ability to produce highly viscous pseudoplastic aqueous solutions even at the low concentrations due to the high molecular weight and the extended repeating unit formed by the hydrogen bonding [1]. There is a host of the chemical processes involving GG which are designed to endow the natural guar gum with a variety of the desired properties. The modification of GG brings about the structural alterations and the introduction of new functional groups. At present, GG is mainly modified by the etherification [2], esterification $[3,4]$, oxidation [5], cross-linking [6], enzymatic hydrolysis [7], and graft [8] in order to improve its performances.
The cross-linking introduced chemically into the polymers will change their swelling power and rheology [9-11]. The cross-linking renders the cross-linked polymer insoluble in the acidic $\mathrm{pH}$ [12]. Generally, there are many kinds of the cross-linking agents used for the polymer modification. For example, the common cross-linking agents used for starch include epichlorhydrin, sodium trimetaphosphate, and phosphorus oxychloride $[13,14]$. At present, the cross-linking agent used for GG modification is usually only borax or glutaraldehyde. Furthermore, the reactive aldehyde groups render the dialdehyde compounds of this type suitable for many applications, for example, as a biocide $[15,16]$, a crosslinker by the reaction with other functional groups such as the hydroxyl and amino groups $[17,18]$, and a corrosion inhibitor for the alloys [19].

Therefore, as mentioned above, the properties of GG modified by composite diol oxidation and cross-linking are also distinctively different from those of guar gum only modified by diol oxidation or cross-linking. In this study, the 
dialdehyde cross-linking guar gum (DCLGG) is obtained by phosphorus oxychloride cross-linking and then sodium periodate oxidation at the controlled temperature, time, $\mathrm{pH}$, and so on. The obtained DCLGG will be used for several industrial applications as a coating in paper, a wet-strength improver in biomaterials, and a strong antiviral biocide in the drug-resistant virus and bacteria, especially a wall material in the target drug carrier in order to avoid or minimize the side effects and to improve the efficacy of the therapy.

When incorporating the polysaccharide in a polymer matrix, its suitable modification is required to increase its compatibility. The functional modification makes modified GG possess the advantage of forming film, compared with GG [20].

Sodium periodate as a highly selective oxidizing agent cleaves the C2 and C3 linkage of the 1,4-anhydro-monosaccharide units with the formation of the dialdehyde groups $[21,22]$. However, most periodate oxidation in the literature was used for starch, cellulose, and konjac glucomannan. Little work has been done to study the compound modification of GG with sodium periodate and phosphorus oxychloride.

The aim of the current study is to investigate the synthesis and optimization of DCLGG, as a novel functional material and its adsorption application. The response surface methodology was used to determine the optimum conditions in order to give the maximum aldehyde content of the cross-linked guar gum. The property and characterization of DCLGG were also studied. Although the oxidation may proceed either on the granule surface or in its interior, the oxidation of crosslinked guar gum with sodium periodate is selected on the granule surface to facilitate the subsequent processing in this study. It results in the fact that functional groups on the surfaces of the GG particles are introduced, where only the hydroxyl groups are substantially cross-linked and oxidized.

\section{Materials and Methods}

2.1. Materials. Guar gum was purchased from Binzhou ZHONGBO Chemical Co., Ltd. L-asparagine was purchased from Chengdu Herbpurify Co., Ltd. Sodium hydroxide, ammonium molybdate, and ethanol were purchased from Shenyang Xinhua Reagent Factory. Phosphorus oxychloride was purchased from Xuzhou Fine Chemical Co., Ltd. Hydrochloric acid was purchased from Shenyang Paier Fine Chemical Co., Ltd. Sodium periodate was purchased from Shenyang Chemical Reagent Factory. Potassium dihydrogen phosphate was purchased from Shenyang Chemical Reagent Factory. Ascorbic acid was purchased from Northeast Pharmaceutical General Factory. Sulfuric acid was purchased from Tianjin City Fuyu Chemical Co., Ltd. Nitric acid was purchased from Shenyang Huizhong Chemical reagent Co., Ltd. All above reagents were of analytical grade.

2.2. Preparation of Cross-Linked Guar Gum (CLGG). $56 \mathrm{~g}$ of dry GG powders (moisture content $=11.0 \%$ ) weighed accurately and $144 \mathrm{~g}$ of ethanol solutions with a mass concentration of $90 \%$ were mixed to produce the guar gum slurry with a mass concentration of $28 \%$ by mass basis. The slurry was put into $250 \mathrm{~mL}$ of the three-necked flask and then stirred and heated to $30^{\circ} \mathrm{C}$ in the water bath. The $\mathrm{pH}$ value of slurry was first adjusted to 11.0 by the sodium hydroxide solutions with a mass concentration of $4 \%$. Five minutes later, $0.6 \mathrm{~g}$ of phosphorus oxychloride was slowly dropped into the slurry under keeping the $\mathrm{pH}$ of the slurry constant by above sodium hydroxide solutions. The reaction was carried out for $1 \mathrm{~h}$. After the reaction ended, the vacuum filtration of the slurry was then conducted. The obtained filtered cake was washed by ethanol aqueous solutions with a mass concentration of $60 \%$ until the $\mathrm{pH}$ of the washed liquid was 6.5 to 7.0 . The resultant cake was dried at $60^{\circ} \mathrm{C}$ for about $2 \mathrm{~h}$ in a 10102 electrothermal constant-temperature dry box (Jintan City Dadi Automation Instrument Factory) so that the moisture content could be less than $12 \%$. The dried cake was ground and screened. Finally, the CLGG was obtained [23]. The formula of guar gum reacting with phosphorus oxychloride was as follows:

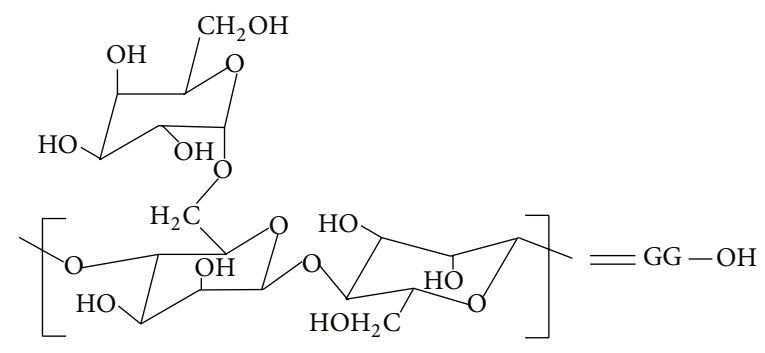

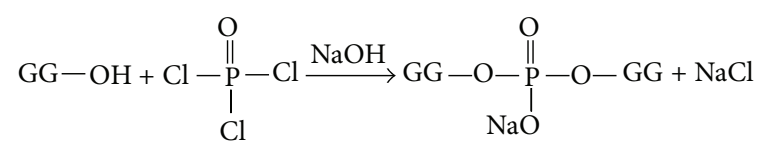

$$
\mathrm{POCl}_{3}+3 \mathrm{H}_{2} \mathrm{O} \longrightarrow \mathrm{H}_{3} \mathrm{PO}_{4}+\mathrm{HCl}
$$

2.3. Preparation of Dialdehyde Cross-Linked Guar Gum (DCLGG). $10 \mathrm{~g}$ of the cross-linking guar gum powders (sedimentation volume $=2.4 \mathrm{~mL}$ or phosphorus content $=0.024 \%$ ) was weighed and then dispersed in sodium periodate aqueous ethanol solutions with a mass concentration of $10 \%$ to produce the guar gum slurry with a concentration of $10 \%$ by mass basis. The $\mathrm{pH}$ value of slurry was adjusted to $2.0-$ 6.0 by $0.1 \mathrm{~mol} / \mathrm{L} \mathrm{HCl}$ and then stirred and heated to $30-50^{\circ} \mathrm{C}$ in the water bath. The reaction was carried out for a certain time. After the reaction ended, the vacuum filtration of the slurry was then conducted. The obtained cake was washed by the ethanol solutions with a mass concentration of $60 \%$ for about four times until there were no periodate ion and iodate ion in the modified guar gum particles. The resultant cake was dried at $60^{\circ} \mathrm{C}$ for about $2 \mathrm{~h}$ in a 1010-2 electrothermal constant-temperature dry box (Jintan City Dadi Automation Instrument Factory) so that the moisture content could be less than $12 \%$. The dried cake was ground and screened. Finally, the DCLGG was obtained [24-26]. The formula of GG reacting with sodium periodate in acidic environment was as follows: 


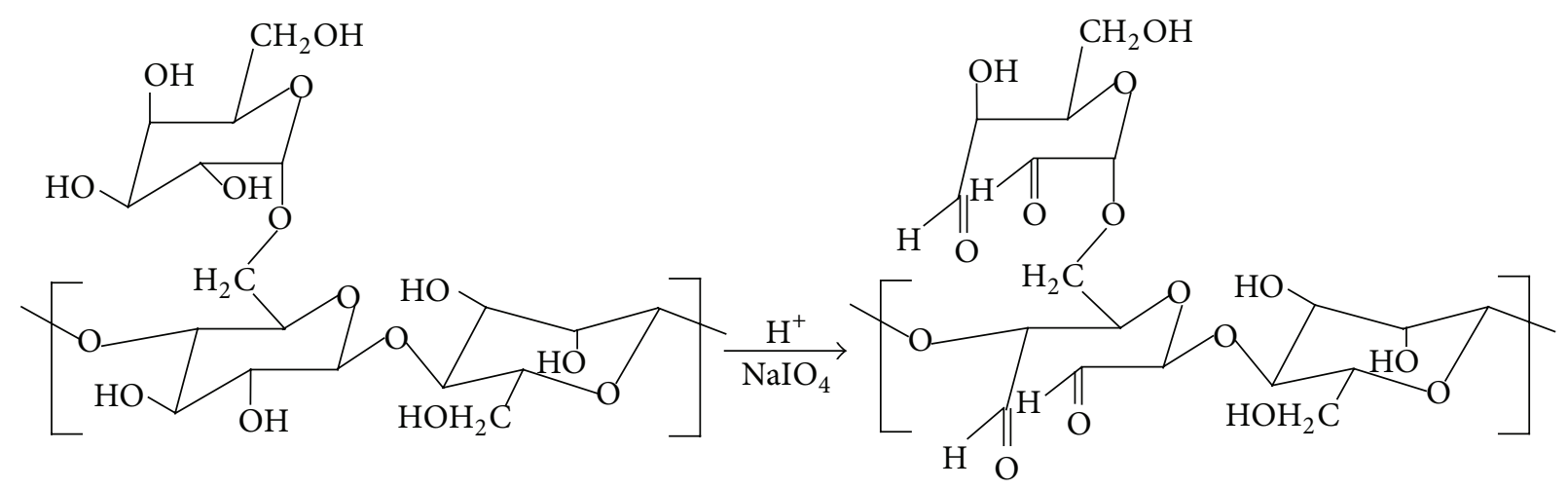

2.4. Sedimentation Volume. $0.2 \mathrm{~g}$ of the dry based sample was weighed and put into a $100 \mathrm{~mL}$ beaker, and then $40 \mathrm{~mL}$ of the distilled water was added. The slurry was heated in the water bath at $85^{\circ} \mathrm{C}$ for $5 \mathrm{~min}$. The distilled water was then added to bring the total weight to be $40.2 \mathrm{~g}$ again. At the same time, the mixture was stirred thoroughly and cooled to the room temperature. $10 \mathrm{~mL}$ of mixture was transferred to two $10 \mathrm{~mL}$ graduated cylinders which were sealed with a cap and centrifuged at $3500 \mathrm{rpm}$ for $10 \mathrm{~min}$. The clear liquid was decanted, and the volume of the clear liquid was determined. The smaller the sedimentation volume was, the bigger the cross-linking degree would be. The sedimentation volume was expressed by the calculation as follows [27, 28]:

$$
V_{s}=10-V,
$$

where $V_{s}$ is the sedimentation volume $(\mathrm{mL})$ and $V$ is the volume of the clear liquid ( $\mathrm{mL})$.

2.5. Aldehyde Content. The aldehyde content was determined using the modified method of the quantitative alkali consumption described by previous study [29, 30]. 0.15-0.20 g of the sample of DCLGG was weighed, transferred to a $100 \mathrm{~mL}$ conical flask, and dispersed in $10 \mathrm{~mL}$ of $0.25 \mathrm{~mol} / \mathrm{L}$ sodium hydroxide. The conical flask was shaken until the slight yellow solutions were obtained. The solutions were placed in the water bath and heated for two minutes at $70^{\circ} \mathrm{C}$ and then rapidly cooled to the room temperature. $15.0 \mathrm{~mL}$ of $0.125 \mathrm{~mol} / \mathrm{L}$ sulphuric acid and $30 \mathrm{~mL}$ of the distilled water were added. Few drops of the phenolphthalein as an indicator were added and titrated with sodium hydroxide $0.25 \mathrm{~mol} / \mathrm{L}$ to the permanent pink color. The aldehyde content was calculated as follows:

$$
\begin{aligned}
& \text { aldehyde content (\%) } \\
& \qquad=\frac{\left(V_{1} \times C_{1}-2 V_{2} \times C_{2}\right) \times 161}{m(1-X)} \times 100 \%,
\end{aligned}
$$

where $m$ is the mass of the sample $(\mathrm{g}), X$ is the moisture content of the sample (\%), $V_{2}$ is the volume of $0.125 \mathrm{~mol} / \mathrm{L}$ $\mathrm{H}_{2} \mathrm{SO}_{4}(\mathrm{~mL}), V_{1}$ is the volume of $0.25 \mathrm{~mol} / \mathrm{L} \mathrm{NaOH}$ used to titrate the sample $(\mathrm{mL}), C_{1}$ is the concentration of $\mathrm{NaOH}$ $(\mathrm{mol} / \mathrm{L})$, and $\mathrm{C}_{2}$ is the concentration of $\mathrm{H}_{2} \mathrm{SO}_{4}(\mathrm{~mol} / \mathrm{L})$.
2.6. Nitrogen Content. The nitrogen content in the samples was determined by the improved Kjeldahl method. The accurately weighed sample $(2.000 \pm 0.05 \mathrm{~g})$ was placed in a digestion flask, and then $2 \mathrm{~g}$ of zinc powders and a few glass beads were added to the flask. After the flask was placed in the inclined position, $20 \mathrm{~mL}$ of concentrated $\mathrm{H}_{2} \mathrm{SO}_{4}$ was added. The flask was shaken until the samples were thoroughly mixed with $\mathrm{H}_{2} \mathrm{SO}_{4}$. The mixture was heated by a heating jacket. When the color of the mixture became green, the digestion flask was removed from a heating jacket and slowly shaken until the sample on the flask wall was washed down into the mixture. Then, the digestion flask was placed back on the heating jacket again. When the color of the mixture was clear blue green and the blue green was maintained for about half an hour, the flask was taken off the heating jacket and cooled to the room temperature. The inner wall of the flask was rinsed with $300 \mathrm{~mL}$ of the distilled water. Afterwards, the flask was connected to a condenser, into which the condensed water was introduced. The distillate was collected by a $300 \mathrm{~mL}$ conical flask containing $30 \mathrm{~mL}$ of $2 \%$ boric acid solutions (w/w) and 3-5 drops of methyl red indicator. The tip of the condenser was immersed in the boric acid solutions. A few zinc granules and $80 \mathrm{~mL}$ of $35 \%$ sodium hydroxide solutions (w/w) were added to the flask under the sealed condition through the funnel. At this time, the liquid in the flak was blue or brown. The hose of adding alkali was tightened in order to completely seal the liquid. The distillation was conducted by the heating jacket. When liquid in the conical flask was $200 \mathrm{~mL}$, the distillation stopped. The condenser's top and end were rinsed two times with little distilled water. The washing liquid was then collected in the conical flask. The distillate in the conical flask was titrated with $0.02 \mathrm{~mol} / \mathrm{L} \mathrm{HCl}$ standard solutions. The blank determination on reagents was corrected. The nitrogen content was calculated as follows [31]:

$$
\text { nitrogen content }(\%)=\frac{\left(V_{1}-V_{0}\right) C \times 0.014}{m(1-X)} \times 100 \text {, }
$$

where $C$ is the concentration of $\mathrm{HCl}$ standard solutions $(\mathrm{mol} / \mathrm{L}), V_{0}$ is the volume of $0.02 \mathrm{~mol} / \mathrm{L} \mathrm{HCl}$ standard solutions to titrate the blank (mol/L), $V_{1}$ is the volume of $0.02 \mathrm{~mol} / \mathrm{L} \mathrm{HCl}$ standard solutions to titrate the samples 
(mol/L), $m$ is the mass of the samples (g), and $X$ is the moisture content of the samples (\%).

2.7. Determination of Phosphorus Content. $0.4395 \mathrm{~g}$ of potassium dihydrogen phosphate weighed exactly was dissolved in $500 \mathrm{~mL}$ of purified water in a $1 \mathrm{~L}$ volumetric flask and diluted to volume with distilled water and mixed thoroughly. $10.0 \mathrm{~mL}$ of the stock solution was pipetted into a $500 \mathrm{~mL}$ volumetric flask and diluted to volume with purified water and mixed thoroughly. The standard phosphorus solution was obtained.

$5.0,10.0,15.0,20.0$, and $25.0 \mathrm{~mL}$ of the standard phosphorus solution (resp., 10, 20, 30, 40, and $50 \mu \mathrm{g}$ of phosphorus) were, respectively, pipetted into respective $50 \mathrm{~mL}$ volumetric flasks. $4 \mathrm{~mL}$ of $2 \%$ ammonium molybdate solutions was added to each of five volumetric flasks. And then $2 \mathrm{~mL}$ of $5 \%$ ascorbic acid solutions and distilled water were added to each of five volumetric flasks to make a total volume of about $45 \mathrm{~mL}$ and mixed thoroughly. The flasks were placed in a boiling water bath for 10 minutes and removed and cooled to $25^{\circ} \mathrm{C}$ in an ice bath. Finally, the above solutions were diluted to a total volume of $50 \mathrm{~mL}$ with distilled water and mixed completely. Each of standard solutions was determined in a $1 \mathrm{~cm}$ cuvette at $825 \mathrm{~nm}$ by a VI-1501 spectrophotometer (Tianjin Gangdong Sci. \& Tech. Development Co., Ltd., China). The equation of the standard curve was expressed as follows:

$$
\begin{aligned}
\text { absorbance }= & 0.02354+0.01171 \\
& \times \text { phosphorus content }(\mu \mathrm{g} / \mathrm{mL}) .
\end{aligned}
$$

$0.300 \mathrm{~g}$ of samples weighed accurately was placed in a $100 \mathrm{~mL}$ digestion flask, and then $15 \mathrm{~mL}$ of mixed acid (volume ratio of concentrated sulfuric acid with a concentration of $96 \%$ to concentrated nitric acid with a concentration of $65 \%$ was equal to 1) was added and well mixed. The mixture in the bottle was heated slowly to the liquid boiling. The mixture was continuously heated until the brown gas was turned white, and the liquid in the bottle became transparent to remove the excess nitric acid solutions. After the above solution was cooled to the room temperature, $45 \mathrm{~mL}$ of distilled water was added to the solutions. The $\mathrm{pH}$ value of the solutions was adjusted to be neutral with $10 \mathrm{~mol} / \mathrm{L}$ sodium hydroxide solutions. And then the solutions in the bottle were moved into a $100 \mathrm{~mL}$ volumetric flask and diluted to a total volume of $100 \mathrm{~mL}$ with distilled water and shaken thoroughly. $25 \mathrm{~mL}$ of the sample solutions was accurately taken into a $50 \mathrm{~mL}$ conical flask. And then $4 \mathrm{~mL}$ of $2 \%$ ammonium molybdate solutions and $2 \mathrm{~mL}$ of $5 \%$ ascorbic acid solutions were pipetted, respectively, into the sample solutions and mixed fully. After the conical flask was placed in a boiling water bath for 10 minutes, it was taken out and cooled to the room temperature in an ice bath. The above liquid was moved into a $50 \mathrm{~mL}$ volumetric flask and diluted to a total volume of $50 \mathrm{~mL}$ with the distilled water and mixed uniformly. The absorbance of the solution was determined with a VI-1501 spectrophotometer (Tianjin Gangdong Sci. \& Tech. Development Co., Ltd., China) at $825 \mathrm{~nm}$ wavelength. The blank determination on the distilled water was corrected.
The calculation formula of the combined phosphorus content was as follows [32]:

$$
\text { phosphorus content }(\%)=\frac{m_{1} \times V_{0} \times 100}{m_{0} \times V_{1} \times 1000} \text {, }
$$

where $m_{0}$ is the mass of the samples $(\mathrm{g}), m_{1}$ is the phosphorus content of the samples obtained from the standard curve (mg), $V_{0}$ is the volume of the sample solutions $(100 \mathrm{~mL})$, and $V_{1}$ is the equal volume of the sample solutions used for the determination $(25 \mathrm{~mL})$.

2.8. Freeze-Thaw Stability. The paste of the sample was prepared by mixing $0.5 \mathrm{~g}$ of GG or its derivative (dry mass) with $99.5 \mathrm{~g}$ of the distilled water. The paste was heated in the water bath to $95^{\circ} \mathrm{C}$ until it became uniform and then cooled to the ambient temperature. $10 \mathrm{~g}$ of the paste weighted precisely was added to each of the preweighed $10 \mathrm{~mL}$ centrifuge tubes, and these paste samples were frozen at $-18^{\circ} \mathrm{C}$ in a BCD-177A freezer (Hefei Meiling Co., Ltd., China) for $24 \mathrm{~h}$. All tubes were removed from the freezer and thawed at $30^{\circ} \mathrm{C}$ in the water bath for $2 \mathrm{~h}$. Three tubes from each thawing cycle of these samples were centrifuged by a TDL802B desk centrifuge (Shanghai Anting Scientific Instrument Factory, China) at $3000 \mathrm{r} / \mathrm{min}$ for $15 \mathrm{~min}$. The clear liquid was decanted, and the residue was weighed. The separated water percentage was then calculated as the ratio of the mass of the decanted liquid to the total mass of the paste before the centrifugation and multiplied by 100 . The low separated water percentage means high freeze-thaw stability $[33,34]$.

2.9. Swelling Power. $0.1 \mathrm{~g}$ of the sample weighed precisely based on the dry sample was added in preweighed $25 \mathrm{~mL}$ of the centrifugal tube; the distilled water was then added to give a total volume of water equivalent to $19.9 \mathrm{~g}$. After that, the centrifugal tube was immediately placed in the water bath whose temperature was controlled at $85^{\circ} \mathrm{C}$ and continuously shaken for $30 \mathrm{~min}$. The centrifugal tube was taken out, wiped dry, and placed on a balance. And then the distilled water was added to the centrifugal tube to bring paste to the total weight of $20 \mathrm{~g}$. After capping, the centrifugal tube was centrifuged by a TDL80-2B desk centrifuge (Shanghai Anting Scientific Instrument Factory, China) at $3000 \mathrm{r} / \mathrm{min}$ for about $15 \mathrm{~min}$. To measure the solubility, $10 \mathrm{~mL}$ of the supernatant was transferred into an evaporating Petri dish and dried overnight in a 1010-2 electrothermal constant-temperature dry box (Jintan City Dadi Automation Instrument Factory, China) at $105^{\circ} \mathrm{C}$. The dried residue was then cooled in the desiccator and weighed for the soluble sample. To measure the swelling power, the residual supernatant was carefully removed and discarded. The bottle with the sediment paste was then weighed to give the weight of the swollen sample granules. The result was expressed by the calculation as [35, 36]:

swelling power (\%)

$$
=\frac{\text { mass of sediment paste } \times 100}{\text { mass of sample on dry basis } \times(100-\% \text { solubility })},
$$


solubility (\%)

$$
=\frac{\text { mass of dried residue of supernatant } \times 100}{\text { mass of sample on dry basis }} .
$$

2.10. Determination of Cold and Hot Viscosity Stability. The cold and hot viscosity refers to the viscosity of samples at $50^{\circ} \mathrm{C}$ and $95^{\circ} \mathrm{C}$, respectively. The viscosity of samples was determined by a NDJ-1 rotational viscometer (Shanghai Precision Instrument Co., Ltd., China). The stability of the viscosity is determined from the following formula:

$$
\begin{aligned}
& \text { stability of viscosity (\%) } \\
& \quad=100 \text { - fluctuation ratio of viscosity (\%). }
\end{aligned}
$$

The fluctuation ratio of the viscosity is expressed as follows:

$$
\text { fluctuation ratio of viscosity (\%) }
$$

$$
=\frac{\max \left|\eta-\eta^{\prime}\right|}{\eta^{\prime \prime}} \times 100
$$

where $\max \left|\eta-\eta^{\prime}\right|$ is the maximum viscosity difference measured by keeping temperature constant for $60 \mathrm{~min}, 90 \mathrm{~min}$, $120 \mathrm{~min}, 150 \mathrm{~min}$, and $180 \mathrm{~min}$, respectively, at $50^{\circ} \mathrm{C}$ or $95^{\circ} \mathrm{C}$. $\eta^{\prime \prime}$ is the viscosity measured by keeping the temperature constant for 1 hour at $95^{\circ} \mathrm{C}$ or $50^{\circ} \mathrm{C}[37,38]$.

2.11. Covalent Binding. $5 \mathrm{~g}$ of DCLGG powders was weighed and then dispersed in $50 \mathrm{~mL}$ of $\mathrm{L}$-asparagine aqueous ethanol solutions (mass ratio of ethanol to water is $5: 4$ ) with a mass concentration of $2 \%$. The $\mathrm{pH}$ value of the suspension was adjusted to 4.0 with $0.1 \mathrm{~mol} / \mathrm{L} \mathrm{HCl}$ and then stirred and heated in the water bath to $45^{\circ} \mathrm{C}$. The binding was carried out for $5 \mathrm{~h}$. The suspension was filtrated, and the obtained filtered cake was washed by ethanol aqueous solutions with a mass concentration of $60 \%$ until the $\mathrm{pH}$ of the washed liquid was down to about 7.0. The resultant cake was dried at $80^{\circ} \mathrm{C}$ for about $5 \mathrm{~h}$ in a 1010-2 electrothermal constant-temperature dry box (Jintan City Dadi Automation Instrument Factory, China) so the moisture content could be less than $12 \%$. The adsorption capacity of DCLGG was determined by the nitrogen content $[39,40]$. The formula of DCLGG reacting with L-asparagine in the weak alkaline environment was as follows:<smiles></smiles>

2.12. Fourier Transform Infrared Spectroscopy (FTIR). An IR Prestige-21 infrared spectrometer with $2 \mathrm{~cm}^{-1}$ resolution (Shimadzu Corporation, Japan) was used to record the FTIR spectra within the range of $4000-400 \mathrm{~cm}^{-1}$. The FTIR spectra were recorded in the solid state using a KB pellet method. The dry sample was blended with $\mathrm{KBr}$ in a ratio sample/KBr $1: 100$. The blend was pressed to obtain a pellet [41].

2.13. Thermal Analysis. The thermal analysis of GG or its derivatives was carried out with a TGA Q50 V20.10 Build 36 thermogravimetric analyzer and a DSC Q20 V24.4 Build 116 differential scanning calorimeter (TA Instruments) in a nitrogen atmosphere. To properly characterize the thermal properties of GG and GG derivatives, the mixture needed to be analyzed in a sealed pan in order to prevent the loss of water from the formulation during heating.

Analysis Conditions of DSC. Sample mass is $4.0-5.0 \mathrm{mg}$, heating rate is $10^{\circ} \mathrm{C} / \mathrm{min}$, temperature range is $10-200^{\circ} \mathrm{C}$, and nitrogen flow is $50.0 \mathrm{~mL} / \mathrm{min}$ [42].

Analysis Conditions of TGA. Sample mass is $6.0-7.0 \mathrm{mg}$, heating rate is $10^{\circ} \mathrm{C} / \mathrm{min}$, temperature range is $10-800^{\circ} \mathrm{C}$, and nitrogen flow is $60.0 \mathrm{~mL} / \mathrm{min}$ [43].
2.14. Particle Morphology. The particle morphology of sample was observed by a XPL-2 transflective polarizing microscope (Nanjing Jiangnan Yongxin Optics Co., Ltd.). The slide with the sample particles was put and moved under the object lens of the polarizing microscope. The appropriate viewing area was selected to observe the size and the shape of the sample particles [44].

2.15. Statistical Analysis. The data were expressed as means of the triplicate determinations. The statistical significance was assessed with one-way analysis of the variance using DesignExpert 6.0.5 for Windows program. The treatment means were considered to have extremely significant difference at $P \leq 0.001$ and significant difference at $P \leq 0.05$.

\section{Results and Discussion}

3.1. Effect of Reaction Time, Reaction Temperature, $p H$, Amount of Sodium Periodate, and Amount of Ethanol on Aldehyde Content of DCLGG. The effect of the reaction time, reaction temperature, $\mathrm{pH}$, amount of sodium periodate, and amount of ethanol on aldehyde content of DCLGG was shown in Figure 1. The amount of sodium periodate was defined as the percentage of the mass ratio of sodium periodate to dry cross-linked guar gum. The amount of ethanol was defined as the percentage of the mass ratio of ethanol to slurry. 


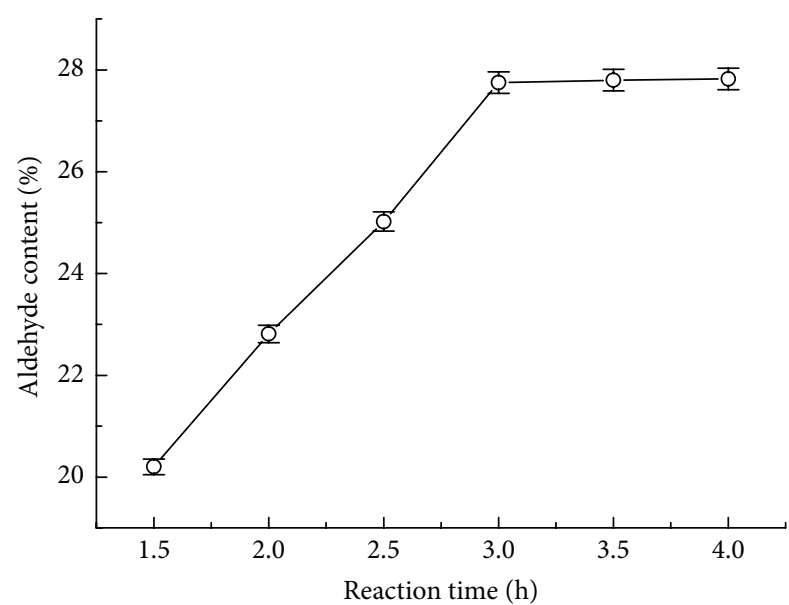

(a) Reaction conditions: reaction temperature $=40^{\circ} \mathrm{C}$, amount of sodium periodate $=30 \%$, amount of ethanol $=77 \%$, and $\mathrm{pH}=4$

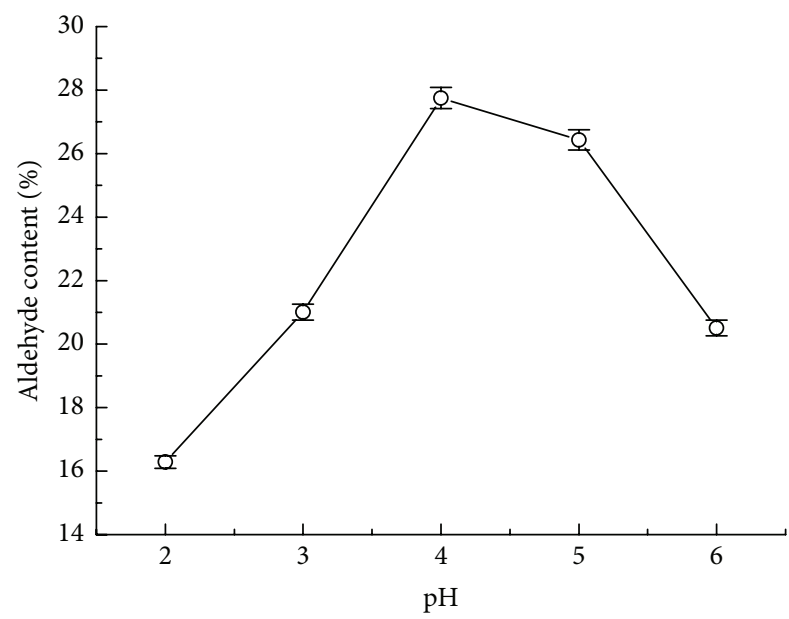

(c) Reaction conditions: reaction time $=3 \mathrm{~h}$, reaction temperature $=$ $40^{\circ} \mathrm{C}$, amount of sodium periodate $=30 \%$, and amount of ethanol $=$ $77 \%$

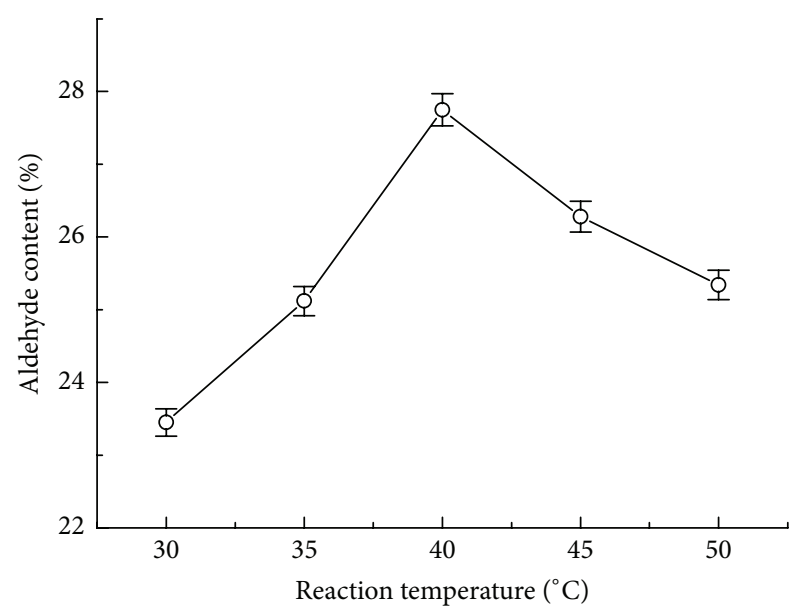

(b) Reaction conditions: reaction time $=3 \mathrm{~h}$, amount of sodium periodate $=30 \%$, amount of ethanol $=77 \%$, and $\mathrm{pH}=4$

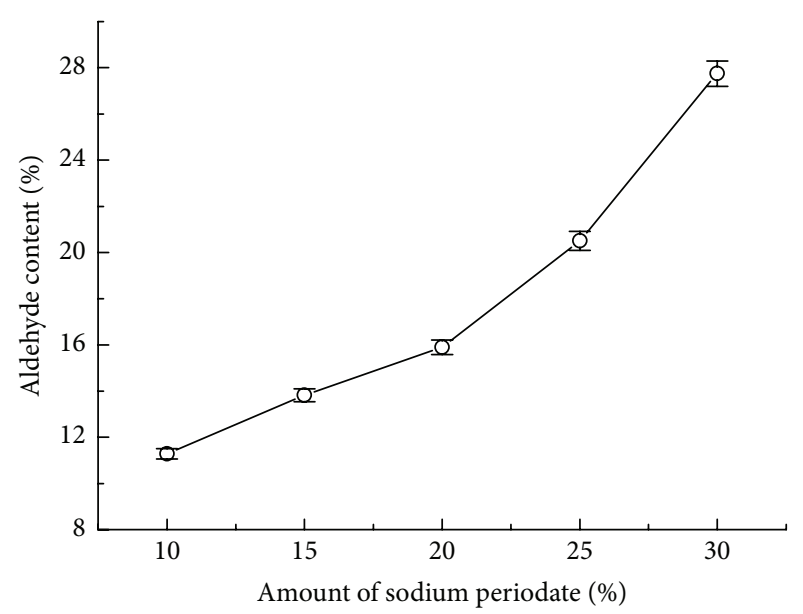

(d) Reaction conditions: reaction time $=3 \mathrm{~h}$, reaction temperature $=$ $40^{\circ} \mathrm{C}, \mathrm{pH}=4$, and amount of ethanol $=77 \%$

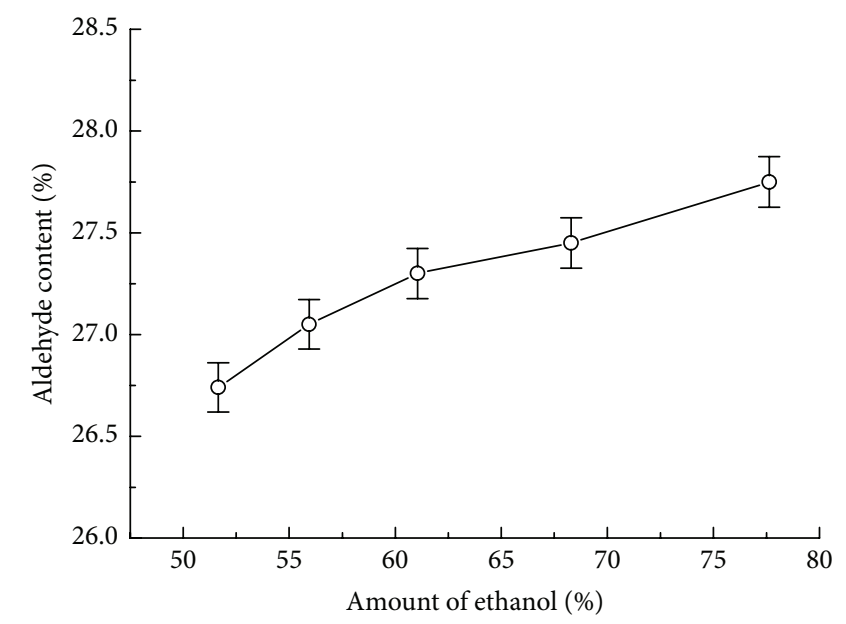

(e) Reaction conditions: reaction time $=3 \mathrm{~h}$, reaction temperature $=40^{\circ} \mathrm{C}$, $\mathrm{pH}=4$, and amount of sodium periodate $=30 \%$

FIGURE 1: Effect of reaction time, reaction temperature, $\mathrm{pH}$, amount of sodium periodate, and amount of ethanol on the aldehyde content of DCLGG. 
From Figure 1(a), the aldehyde content of DCLGG increased with increasing the reaction time when the reaction time was less than $3.0 \mathrm{~h}$. The aldehyde content of DCLGG did not change basically with the increase of the reaction time when the reaction time was more than $3 \mathrm{~h}$. The causes for this could be explained as follows. As the reaction time increased, the increase of the effective contact between the molecules of GG and molecules of sodium periodate promoted the oxidization reaction. However, the sodium periodate was depleted as the oxidization reaction proceeded. The oxidization reaction would not continue when the concentration of sodium periodate was reduced to a certain value. So the suitable reaction time was considered to be $3 \mathrm{~h}$.

The reaction temperature was varied from 30 to $50^{\circ} \mathrm{C}$ to examine the temperature effects. From Figure 1(b), when the reaction temperature was less than $40^{\circ} \mathrm{C}$, the aldehyde content of DCLGG increased with increasing the reaction temperature. When the reaction temperature was more than $40^{\circ} \mathrm{C}$, however, the aldehyde content of DCLGG decreased with increasing the reaction temperature. The reason might be explained as follows: as the reaction temperature increased, the thermal motion of sodium periodate molecules was accelerated, which was in favor of the diffusion of sodium periodate into the particles. It resulted in the more hydroxyl groups on GG particles being oxidized. On the other hand, the elevated temperature would lead to the more side reaction of sodium periodate and the large expansion of the GG grains, which reduced the number of the holes on the GG grains. As a result, the reaction temperature influenced the oxidization. So, the suitable reaction temperature was considered to be $40^{\circ} \mathrm{C}$.

The $\mathrm{pH}$ was varied from 2 to 6 to examine the effects of the $\mathrm{pH}$. From Figure 1(c), when the $\mathrm{pH}$ was less than 4, the aldehyde content of DCLGG increased with increasing the $\mathrm{pH}$. When the $\mathrm{pH}$ value was more than 4 , however, the aldehyde content of DCLGG decreased with increasing the $\mathrm{pH}$. The causes for this could be explained as follows: during the oxidization, sodium periodate was first obliged to be transformed into the periodic acid under the acid condition, and then the oxidization of CLGG was able to be carried out. Therefore, when the $\mathrm{pH}$ value was more than 4 , it was not in favor of the transformation of sodium periodate into the periodic acid. This resulted in the efficiency of the oxidization to be lowered. But the degree of the acetal or hemiacetal cross-linking formation increased because the aldehyde group reacted with the hydroxyl group between DCLGG molecules or within DCLGG molecules when the $\mathrm{pH}$ of the oxidization was less than 4 . So, the suitable $\mathrm{pH}$ was considered to be 4 in this system.

The amount of sodium periodate was varied from $10 \%$ to $30 \%$ to examine the effects of sodium periodate. From Figure 1(d), the aldehyde content of DCGG increased with the increase of the amount of sodium periodate. The effective collision was proportional to the concentration of reactants, and reaction rate was proportional to the collision frequency. When the amount of sodium periodate was very low, the collision frequency decreased, which led to a very low reaction rate. So, the amount of sodium periodate was selected to be $30 \%$ for considering the actual needs of DCGG.
TABLE 1: Factors and levels of response surface test for DCLGG.

\begin{tabular}{lcccc}
\hline $\begin{array}{l}\text { Factors } \\
\text { and } \\
\text { levels }\end{array}$ & $\begin{array}{c}\text { Reaction } \\
\text { temperature } \\
(A) /{ }^{\circ} \mathrm{C}\end{array}$ & $\begin{array}{c}\text { Reaction } \\
\text { time }(B) / \mathrm{h}\end{array}$ & $\mathrm{pH}(C)$ & $\begin{array}{c}\text { Amount } \\
\text { of } \\
\text { ethanol } \\
(D) / \%\end{array}$ \\
\hline-1 & 35 & 2.5 & 3 & 61 \\
0 & 40 & 3.0 & 4 & 68 \\
1 & 45 & 3.5 & 5 & 77 \\
\hline
\end{tabular}

During sodium periodate oxidization, the action of ethanol as a solvent only kept GG in a granular form. The amount of ethanol was varied from $51 \%$ to $78 \%$ to examine the effects of ethanol at the fixed other parameters. From Figure 1(e), the aldehyde content of DCLGG increased with the increase of the amount of ethanol. But the aldehyde content of DCLGG was changed slightly with the increase of the amount of ethanol. And the value, where the amount of ethanol reached $78 \%$, was basically close to the maximum in this system. So, the amount of ethanol was selected to be $78 \%$.

\subsection{Optimization of Processing Parameters}

3.2.1. Design and Results of Response Surface Test. The process parameters for preparing DCLGG were further optimized using the dialdehyde content as the response value by the Box-Behnken design, which was used to develop a correlation between the condition variables and the dialdehyde content. The factors and levels of the response surface test for DCLGG were shown in Table 1. Accordingly, the design and results of the response surface test were shown in Table 2. The amount of sodium periodate was held at $30 \%$.

3.2.2. Mathematical Model and Variance Analysis. By applying multiple regression analysis on the experimental data, the second-order response surface model for preparing DCLGG was as follows:

$$
\begin{aligned}
Y= & 27.4-0.068 A+1.5 B+1.14 C+1.55 D-0.93 A^{2} \\
& -2.8 B^{2}-4.41 C^{2}-1.13 D^{2}+0.0075 A B \\
& +0.39 A C+1.11 A D+0.89 B C-1.32 B D \\
& +1.43 C D
\end{aligned}
$$

where $Y$ is the predicted response, that is, the aldehyde content, and $A, B, C$, and $D$ are the test variables such as the reaction temperature, reaction time, $\mathrm{pH}$, and amount of ethanol, respectively.

The analysis of the variance (ANOVA) was performed to check the significance of the fit of the second-order polynomial equation for the experimental data, and the results were given in Table 3. From Table 3, the prob. level of the regression with a very low probability value $(<0.0001)$ indicated that the model was highly significant. The goodness of fit of the model was checked by the determination coefficient $\left(R^{2}\right)$ of $99.03 \%$. In this case, $R^{2}$ value $(0.9903)$ for the above equation indicated that the sample variation for DCLGG of $99.03 \%$ 
TABLE 2: Design and results of response surface test for DCLGG.

\begin{tabular}{|c|c|c|c|c|c|}
\hline Test numbers & $A$ & $B$ & $C$ & $D$ & Aldehyde content $/ \%$ \\
\hline 1 & 45.00 & 3.50 & 4.00 & 71.00 & 25.12 \\
\hline 2 & 40.00 & 3.00 & 4.00 & 71.00 & 27.5 \\
\hline 3 & 40.00 & 3.50 & 4.00 & 63.00 & 25.08 \\
\hline 4 & 45.00 & 2.50 & 4.00 & 71.00 & 22.39 \\
\hline 5 & 35.00 & 3.00 & 5.00 & 71.00 & 23.56 \\
\hline 6 & 35.00 & 3.00 & 4.00 & 78.00 & 25.12 \\
\hline 7 & 45.00 & 3.00 & 4.00 & 78.00 & 27.61 \\
\hline 8 & 45.00 & 3.00 & 3.00 & 71.00 & 20.51 \\
\hline 9 & 35.00 & 3.00 & 4.00 & 63.00 & 24.82 \\
\hline 10 & 40.00 & 3.50 & 5.00 & 71.00 & 23.36 \\
\hline 11 & 45.00 & 3.00 & 5.00 & 71.00 & 23.97 \\
\hline 12 & 35.00 & 3.50 & 4.00 & 71.00 & 25.09 \\
\hline 13 & 40.00 & 3.50 & 4.00 & 78.00 & 25.49 \\
\hline 14 & 40.00 & 3.00 & 4.00 & 71.00 & 27.5 \\
\hline 15 & 40.00 & 2.50 & 4.00 & 63.00 & 19.36 \\
\hline 16 & 40.00 & 2.50 & 3.00 & 71.00 & 18.5 \\
\hline 17 & 40.00 & 3.00 & 5.00 & 63.00 & 19.82 \\
\hline 18 & 45.00 & 3.00 & 4.00 & 63.00 & 22.82 \\
\hline 19 & 40.00 & 3.00 & 4.00 & 71.00 & 27.5 \\
\hline 20 & 40.00 & 3.50 & 3.00 & 71.00 & 19.59 \\
\hline 21 & 40.00 & 3.00 & 3.00 & 78.00 & 21.01 \\
\hline 22 & 40.00 & 3.00 & 5.00 & 78.00 & 26.43 \\
\hline 23 & 40.00 & 2.50 & 4.00 & 78.00 & 25.02 \\
\hline 24 & 40.00 & 3.00 & 4.00 & 71.00 & 27.5 \\
\hline 25 & 40.00 & 3.00 & 4.00 & 71.00 & 27.5 \\
\hline 26 & 40.00 & 3.00 & 3.00 & 63.00 & 20.14 \\
\hline 27 & 35.00 & 3.00 & 3.00 & 71.00 & 21.66 \\
\hline 28 & 35.00 & 2.50 & 4.00 & 71.00 & 22.39 \\
\hline 29 & 40.00 & 2.50 & 5.00 & 71.00 & 18.72 \\
\hline
\end{tabular}

was attributed to the independent variables and only $0.97 \%$ of the total variation cannot be explained by the model. The adjusted determination coefficient (adj. $R^{2}=0.9805$ ) was also satisfactory for confirming the significance of the model.

The probability level was used as a tool to check the significance of each of the coefficients. Smaller $P$ value denoted the greater significance of the corresponding coefficient. From the variance analysis in Table 3 , it was possible to identify factors affecting the relative importance of the aldehyde content. The order from the primary to secondary was the amount of ethanol, reaction time, $\mathrm{pH}$, and reaction temperature in turn. The independent variable $(B, C, D)$, squared variables $\left(A^{2}, B^{2}, C^{2}, D^{2}\right)$, and interaction $(B D, B C, C D)$ had a high significant effect. All the independent variables had a positive coefficient except for the variable $(A)$. The negative signs of the independent variable $(A)$, the $B D$ interaction, and squared variables $\left(A^{2}, B^{2}, C^{2}, D^{2}\right)$ revealed a reduction in the aldehyde content when these corresponding variables were increased. However, the independent variable $(A)$ and interaction $(A B, A C, A D)$ were not significant. So the equation discussed above was further simplified as

$$
\begin{aligned}
Y= & 2.74+1.5 B+1.14 C+1.55 D-0.93 A^{2}-2.8 B^{2} \\
& -4.41 C^{2}-1.13 D^{2}+0.89 B C-1.32 B D \\
& +1.43 C D
\end{aligned}
$$

The optimal values of $\mathrm{pH}$, amount of ethanol, reaction temperature, and time estimated in actual units were 4.1, $74.52 \%, 39.88^{\circ} \mathrm{C}$, and $3.04 \mathrm{~h}$, respectively, with the predicted aldehyde content of $28.1 \%$. According to the realistic conditions, the $\mathrm{pH}$, amount of ethanol, reaction temperature, and reaction time were adjusted to $4.0,74.5 \%, 40^{\circ} \mathrm{C}$, and $3.0 \mathrm{~h}$, respectively.

3.2.3. Interaction of Variables. The response surfaces as the function of two variables at the center level of other variables 
TABLE 3: Variance analysis of response surface test.

\begin{tabular}{|c|c|c|c|c|c|c|}
\hline Source & Square sum & Freedom degree & Mean square & $F$-ratio & Prob. level & Significance level \\
\hline Regression & 247.69 & 14 & 17.69 & 101.59 & $<0.0001$ & $* *$ \\
\hline$A$ & 0.055 & 1 & 0.055 & 0.31 & 0.5843 & \\
\hline$B$ & 27.0 & 1 & 27.0 & 155.01 & $<0.0001$ & $* *$ \\
\hline C & 15.52 & 1 & 15.52 & 89.14 & $<0.0001$ & $* *$ \\
\hline$D$ & 28.95 & 1 & 29.95 & 166.25 & $<0.0001$ & $* *$ \\
\hline$A^{2}$ & 5.65 & 1 & 5.65 & 32.44 & $<0.0001$ & $* *$ \\
\hline$B^{2}$ & 50.93 & 1 & 50.93 & 292.44 & $<0.0001$ & $* *$ \\
\hline$C^{2}$ & 125.98 & 1 & 125.98 & 723.39 & $<0.0001$ & $* *$ \\
\hline$D^{2}$ & 8.15 & 1 & 8.15 & 46.8 & $<0.0001$ & $* *$ \\
\hline$A B$ & 0.00023 & 1 & 0.00023 & 0.00129 & 0.9718 & \\
\hline$A C$ & 0.61 & 1 & 0.61 & 3.49 & 0.0827 & \\
\hline$A D$ & 3.15 & 1 & 4.94 & 28.37 & 0.0011 & \\
\hline$B C$ & 4.94 & 1 & 3.15 & 18.09 & $<0.0001$ & $* *$ \\
\hline$B D$ & 6.94 & 1 & 6.94 & 39.86 & $<0.0001$ & $* *$ \\
\hline$C D$ & 8.16 & 1 & 8.16 & 46.85 & $<0.0001$ & $* *$ \\
\hline Residuals & 2.44 & 14 & 0.17 & & & \\
\hline Lack of fit & 2.44 & 10 & 0.24 & & & \\
\hline Pure error & 0.000 & 4 & 0.000 & & & \\
\hline Sum & 10.75 & 28 & & & & \\
\hline
\end{tabular}

** Extremely significant difference at $P \leq 0.001$. Note: significant difference at $P \leq 0.05$.

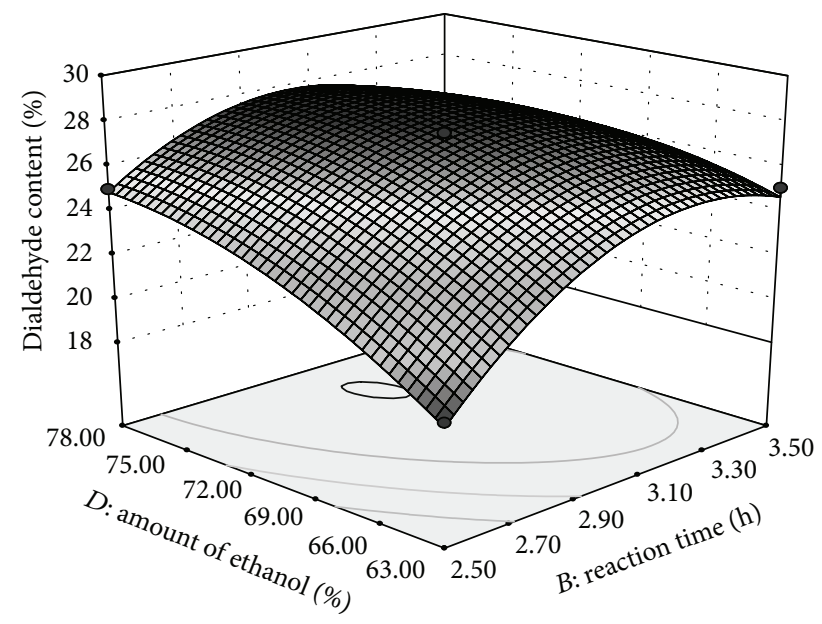

FIGURE 2: Mutual effect of amount of ethanol and reaction time at fixed $\mathrm{pH}$ of 4 and reaction temperature of $40^{\circ} \mathrm{C}$.

were shown in Figures 2, 3, and 4, respectively. The threedimensional response surface plot was a 3D graphic representation of the regression equation showing the individual and cumulative effect of the variable and the mutual interaction between the variables.

From Figure 2, the aldehyde content of DCLGG increased with increasing the amount of ethanol when the $\mathrm{pH}$ and reaction temperature were fixed at 4 and $40^{\circ} \mathrm{C}$, respectively. But the influence of the reaction time on the aldehyde content of DCLGG was different from the amount of ethanol with increasing the reaction time. The aldehyde content of

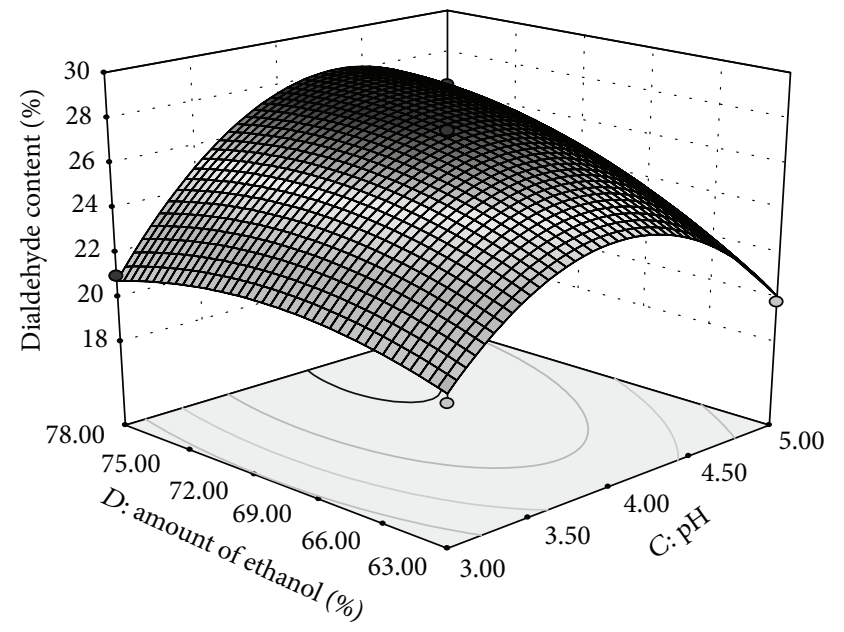

Figure 3: Mutual effect of amount of ethanol and $\mathrm{pH}$ at fixed reaction temperature of $40^{\circ} \mathrm{C}$ and reaction time of $3 \mathrm{~h}$.

DCLGG was found to first increase with the increase of the reaction time from 2.5 to 3.0 and thereafter decreased with the further increase of the reaction time from 3.0 to 3.5.

From Figure 3, the response surface as the function of the amount of ethanol and $\mathrm{pH}$ was obviously different from the response surface as the function of the amount of ethanol and reaction time when the reaction temperature and reaction time were fixed at $40^{\circ} \mathrm{C}$ and $3 \mathrm{~h}$, respectively. The aldehyde content of DCLGG was obviously influenced by the $\mathrm{pH}$, compared with the amount of ethanol. 


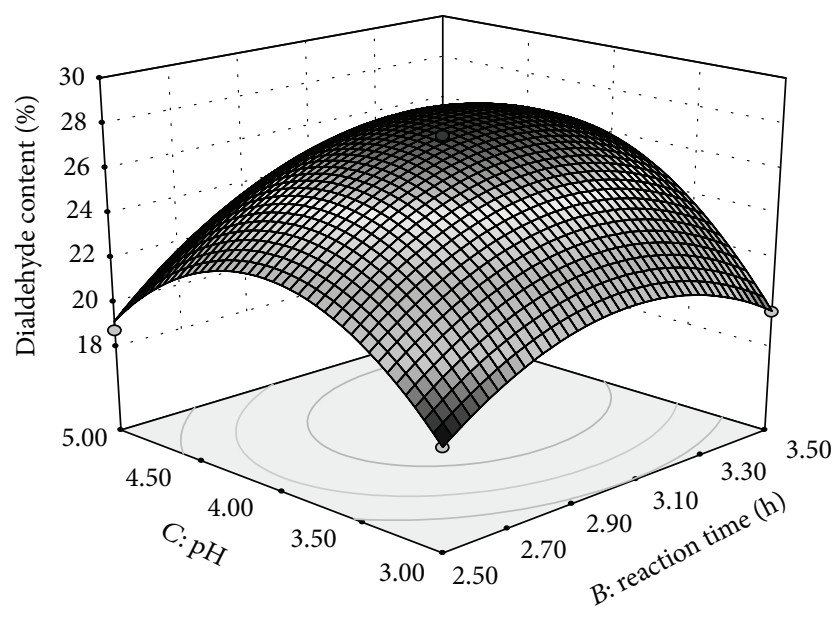

FIgURE 4: Mutual effect of reaction time and $\mathrm{pH}$ at fixed reaction temperature of $40^{\circ} \mathrm{C}$ and amount of ethanol of $74.5 \%$.

From Figure 4, the effect of the $\mathrm{pH}$ or reaction time on the aldehyde content of DCLGG displayed first the increase and then the decrease with increasing the $\mathrm{pH}$ or reaction time when the reaction temperature and amount of ethanol were fixed at $40^{\circ} \mathrm{C}$ and $74.5 \%$, respectively. The response surface was like the parabolic surface.

3.2.4. Verification of Model. The parallel test was conducted three times under the above adjusted optimal parameters again. The mean experimental value for the aldehyde content of DCLGG was obtained to be $27.75 \%$ under these optimum conditions, which was $1.3 \%$ lower than the predicted value. It revealed the high accuracy of the model.

3.3. Relationship between Sedimentation Volume and Phosphorus Content. The relationship of sedimentation volume and phosphorus content for CLGG was shown in Table 4. From Table 4, the sedimentation volume decreased with increasing the phosphorus content. The smaller the sedimentation volume was, the bigger the cross-linking degree was. It proved that the cross-linking degree of GG was expressed indirectly by the sedimentation volume.

3.4. Effect of Cross-Linking and Oxidation on Freeze-Thaw Stability and Swelling Power. The freeze-thaw stability and swelling power of GG, CLGG (sedimentation volume = $2.4 \mathrm{~mL}$ ), DGG (aldehyde content $=24.7 \%$ ), and DCLGG (aldehyde content $=24.7 \%$; sedimentation volume $=2.4 \mathrm{~mL}$ ) were shown in Table 5. The high separated water percentage meant the poor freeze-thaw stability. When the paste of GG, CLGG, DGG, and DCLGG was frozen, the phase separation occurred with the formation of the ice crystals. The extent of the phase separation increased with increasing the additional freeze-thaw cycles. From Table 5, the cross-linking and oxidization increased the freeze-thaw stability of GG. The cross-linking only increased the swelling power of GG, which improved dramatically its release effect. However, the oxidization decreased the swelling power of GG. It resulted in the fact that the swelling power of DCLGG was between the
TABLE 4: The relationship between sedimentation volume and phosphorus content for CLGG.

\begin{tabular}{lc}
\hline Samples & Phosphorus content $/ \%$ \\
\hline CLGG (sedimentation volume $=3.5 \mathrm{~mL})$ & 0.0163 \\
CLGG $($ sedimentation volume $=2.4 \mathrm{~mL})$ & 0.0240 \\
CLGG $($ sedimentation volume $=1.3 \mathrm{~mL})$ & 0.0495 \\
\hline
\end{tabular}

TABLE 5: Effect of cross-linking and oxidation on freeze-thaw stability and swelling power of GG.

\begin{tabular}{lcc}
\hline Samples & Separated water percentage/\% & Swelling power/\% \\
\hline GG & 94.7 & 39.0 \\
CLGG & 82.9 & 51.3 \\
DGG & 84.8 & 21.6 \\
DCLGG & 80.6 & 34.1 \\
\hline
\end{tabular}

TABLE 6: Effect of cross-linking and oxidation on cold and hot viscosity stability of GG.

\begin{tabular}{lccc}
\hline Samples & Viscosity/mPa·s & $\begin{array}{c}\text { Cold } \\
\text { viscosity } \\
\text { stability/\% }\end{array}$ & $\begin{array}{c}\text { Hot viscosity } \\
\text { stability/\% }\end{array}$ \\
\hline GG & 428.0 & 93.3 & 91.3 \\
CLGG & 246.0 & 56.1 & 48.6 \\
DGG & 40.2 & 84.4 & 87.3 \\
DCLGG & 4.1 & 44.5 & 45.7 \\
\hline
\end{tabular}

swelling power of CLGG and the swelling power of DGG. The cross-linking made up the reduction of the swelling power of GG owing to the oxidization.

3.5. Effect of Cross-Linking and Oxidation on Cold and Hot Viscosity Stability. The cold viscosity stability and hot viscosity stability of GG, CLGG (sedimentation volume = $2.4 \mathrm{~mL}$ ), DGG (aldehyde content $=24.7 \%$ ), and DCLGG (aldehyde content $=24.7 \%$; sedimentation volume $=2.4 \mathrm{~mL}$ ) were shown in Table 6. From Table 6, the cross-linking and oxidation reduced the viscosity of GG. It suggested that the paste of the derivatives had the high solid content. After GG was cross-linked or oxidized, the fluctuation ratios of the cold viscosity and hot viscosity all decreased. The fluctuation ratio of the hot viscosity was less than that of the cold viscosity. The magnitude of the cold viscosity and hot viscosity fluctuation ratios from big to small in order was GG, DGG, DCLGG, and CLGG. It suggested that the change of the hot viscosity fluctuation was in accordance with the cold viscosity fluctuation. The cross-linking and diol oxidation reduced the viscosity of GG. The situation was very helpful to form a coherent film on the surface of the substrate under the prevailing conditions. And the low viscosity was in favor of the drug coating.

3.6. Effect of Cross-Linking and Oxidation on FTIR of GG. FTIR spectra of GG, CLGG (sedimentation volume = $2.4 \mathrm{~mL}$ ), and DCLGG (aldehyde content $=24.7 \%$; sedimentation volume $=2.4 \mathrm{~mL}$ ) were shown in Figure 5. From Figure 5, the absorption peaks of GG, CLGG, and DCLGG at the wave number of $3400 \mathrm{~cm}^{-1}$ were due to the stretching 
TABLE 7: Onset temperature, peak temperature, end temperature, and melting enthalpy.

\begin{tabular}{lcccc}
\hline Sample & Onset temperature $/{ }^{\circ} \mathrm{C}$ & Peak temperature $/{ }^{\circ} \mathrm{C}$ & End temperature $/{ }^{\circ} \mathrm{C}$ & Melting enthalpy $/ J \cdot \mathrm{g}^{-1}$ \\
\hline GG & 52.6 & 104.6 & 162.33 & 367.8 \\
CLGG & 61.1 & 112.1 & 170.84 & 318.2 \\
DCLGG & 55.0 & 115.3 & 171.36 & 334.7 \\
\hline
\end{tabular}

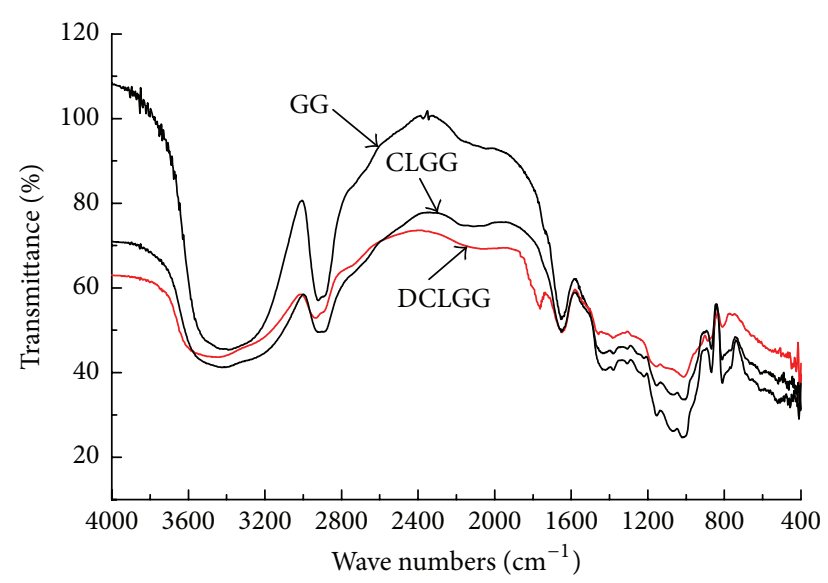

FIgURE 5: IR spectra of GG, CLGG, and DCLGG.

vibration of the $\mathrm{O}-\mathrm{H}$ groups. The peak intensity of the $\mathrm{O}-$ $\mathrm{H}$ groups in the FTIR curves of CLGG and DCLGG was obviously different from the intensity in the FTIR curves of GG. The intensity of the O-H groups in the FTIR curves of CLGG and DCLGG was less than that of GG. However, the intensity of the O-H groups of CLGG was almost the same as that of DCLGG. It proved that the cross-linking obviously reduced the numbers of the O-H groups in GG molecules. The oxidization could not obviously change the intensity of the O-H groups of CLGG. The absorption peak of GG, CLGG, and DCLGG at the wave number of $2920 \mathrm{~cm}^{-1}$ belonged to the stretching vibration of the $\mathrm{C}-\mathrm{H}$ bond. The peak intensity of the C-H bond of CLGG and DCLGG was obviously less than that of GG owing to the $\mathrm{P}=\mathrm{O}$ bond. The absorption peak of DCLGG at the wave number of $1760 \mathrm{~cm}^{-1}$ was attributed to the characteristic peak of the $\mathrm{C}=\mathrm{O}$ bond. It proved that the aldehyde group was successfully introduced into the molecules of GG owing to the oxidization. However, there was no difference between GG and CLGG except for the peak intensity. It suggested that the P-O-C bond in the molecules of CLGG was not determined by the infrared spectroscopy.

3.7. DSC and TGA Analysis. The DSC and TGA curves of GG, CLGG (sedimentation volume $=2.4 \mathrm{~mL}$ ), and DCLGG (aldehyde content $=24.7 \%$; sedimentation volume $=2.4 \mathrm{~mL}$ ) were shown in Figure 6. According to Figure 6, after GG was modified by the cross-linking or oxidization, its onset temperature, peak temperature, end temperature, melting enthalpy, and thermal stability all were changed. The specific parameters calculated from the above-mentioned figures were listed in Tables 7 and 8. The thermogravimetric analysis of GG, CLGG, and DCLGG essentially revealed two distinct zones of the mass loss. The initial mass loss occurred due
TABle 8: Onset decomposition temperature, end decomposition temperature, and mass loss rate.

\begin{tabular}{lccc}
\hline Sample & $\begin{array}{c}\text { Onset } \\
\text { decomposition } \\
\text { temperature } /{ }^{\circ} \mathrm{C}\end{array}$ & $\begin{array}{c}\text { End } \\
\text { decomposition } \\
\text { temperature } /{ }^{\circ} \mathrm{C}\end{array}$ & Rate of mass loss/\% \\
\hline GG & 279.8 & 327.1 & 69.0 \\
CLGG & 275.7 & 316.5 & 62.4 \\
DCLGG & 276.9 & 322.9 & 60.4 \\
\hline
\end{tabular}

to the moisture presented in the samples. The second step represented the degradation of the polymer backbone.

The DSC curves of the polymers showed their specific endothermic peaks and melted enthalpy, which were helpful in determining the fitness of the polymers with the active compounds. From Table 7, the onset temperature, peak temperature, and end temperature of CLGG or DCLGG were more than those of GG. The melting enthalpy of CLGG or DCLGG was less than that of GG. In particular, the peak temperature and end temperature of DCLGG were more than those of CLGG. The cross-liking reduced the melting enthalpy of GG. However, the oxidization increased the melting enthalpy of CLGG. In the meantime, the cross-linking increased the onset temperature of GG. But the oxidization reduced the onset temperature of CLGG.

From Table 8, the onset decomposition temperature, end decomposition temperature, and rate of mass loss of GG were reduced by the cross-linking or the oxidization. However, the onset decomposition temperature and end decomposition temperature of CLGG were increased by the oxidization. The data of mass loss rate proved that the thermal stability of GG was increased by the cross-linking or the oxidization.

3.8. Morphology Analysis. The polarizing microscope photos of GG, CLGG (sedimentation volume $=2.4 \mathrm{~mL}$ ), and DCLGG (aldehyde content $=24.7 \%$; sedimentation volume $=2.4 \mathrm{~mL}$ ) were shown in Figure 7. From Figure 7, there was no Maltese cross on the surface of the GG particles. The refraction of the polarized light on GG particles belonged to a single refraction. The cross-linking did not change obviously the morphology of GG particles, which displayed a linear shape. The morphology of the DCLGG particles, however, was different from that of GG, and most of the DCLGG particles were of a block shape. It suggested that the particles of GG and CLGG did swell owing to the oxidization. The appearance and size of GG granules were influenced by the aldehyde oxidization. It proved that the sodium periodate oxidization might be carried out not only on the surface of GG particles but also in its interior. 


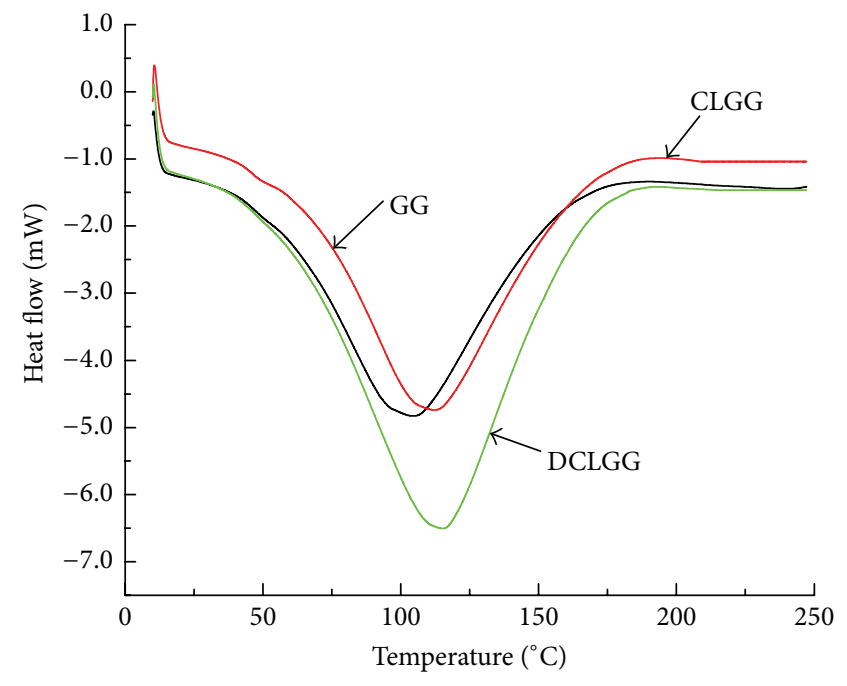

(a)

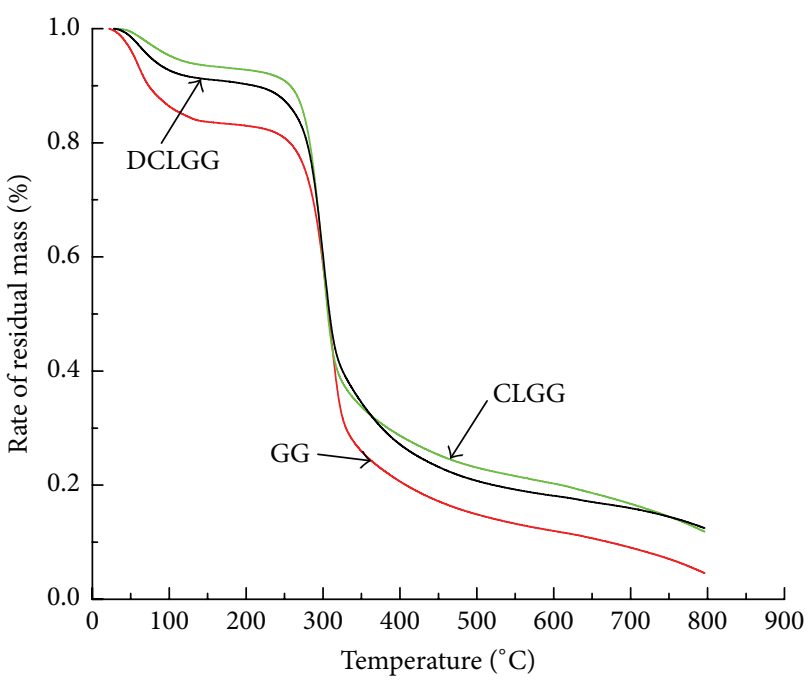

(b)

Figure 6: DSC (a) and TGA (b) curves of GG, CLGG, and DCLGG.

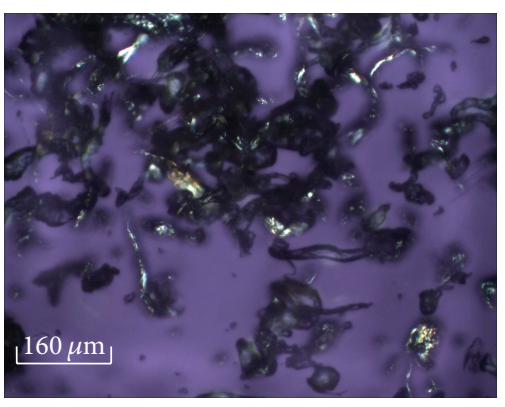

(a)

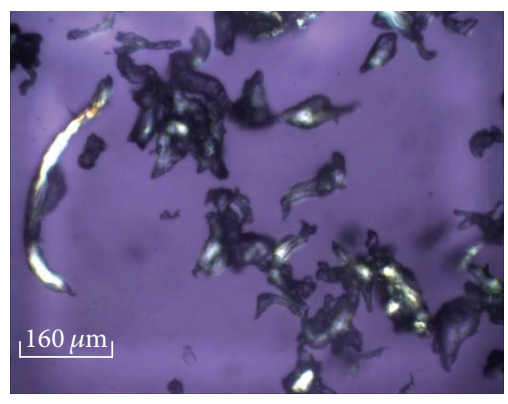

(b)

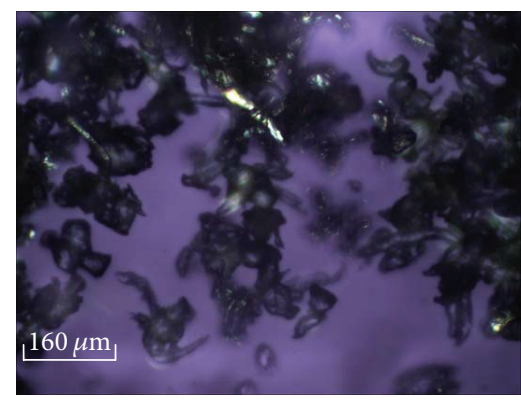

(c)

Figure 7: Polarizing microscope photos of GG (a), CLGG (b), and DCLGG (c).

3.9. Binding of L-Asparagine. The binding curve of $\mathrm{L}$ asparagine on DCLGG ((a) aldehyde content = 14.7\%; (b) aldehyde content $=26.2 \%$ ) granules was shown in Figure 8. The binding capacity of DCLGG was determined by the improved Kjeldahl method. From Figure 8, the adsorption capacity of DCLGG with aldehyde content of $26.2 \%$ was more than that of DCLGG with aldehyde content of $14.7 \%$. The adsorption capacity of DCLGG increased with the increase in the adsorption time when the adsorption time was less than $4 \mathrm{~h}$. For the adsorption curve of L-asparagine on DCLGG with aldehyde content of $26.2 \%$, the adsorption capacity of DCLGG was not changed basically with increasing the adsorption time when the adsorption time was more than $5 \mathrm{~h}$. The maximum adsorption capacity of L-asparagine on DCLGG with aldehyde content of $26.2 \%$ reached $21.9 \mathrm{mg} / \mathrm{g}$, which is obviously greater than that of the anticancer drug called doxorubicin on the dialdehyde starch nanoparticle carriers [45]. Accordingly, the maximum adsorption capacity of L-asparagine on DCLGG with aldehyde content of $14.7 \%$ was only $15.3 \mathrm{mg} / \mathrm{g}$. The above results suggested that $\mathrm{L}-$ asparagine was chemically bound well by DCLGG.

\section{Conclusions}

The importance order of the oxidization of cross-linking guar gum from the primary to the secondary was the amount of ethanol, reaction time, $\mathrm{pH}$, and reaction temperature. The effect of the interaction between the reaction time and $\mathrm{pH}$, reaction time and amount of ethanol, and amount of ethanol and $\mathrm{pH}$ on the aldehyde content of dialdehyde cross-linking guar gum was extremely significant. The best technological conditions for preparing dialdehyde cross-linked guar gum were as follows: reaction temperature of $40^{\circ} \mathrm{C}$, reaction time of $3.0 \mathrm{~h}, \mathrm{pH}$ of 4.0 , and amount of ethanol of $74.5 \%$. The optimum oxidization conditions shown in this study can be further exploited to prepare the industrial products by providing much more opportunity for the multiapplications of DCLGG. The cross-linking increased the freeze-thaw stability, swelling power, and cold viscosity stability and hot viscosity stability of GG. The dialdehyde oxidization also increased the freeze-thaw stability and cold viscosity stability and hot viscosity stability of GG but decreased the swelling power of GG. The thermal stability of GG was increased 


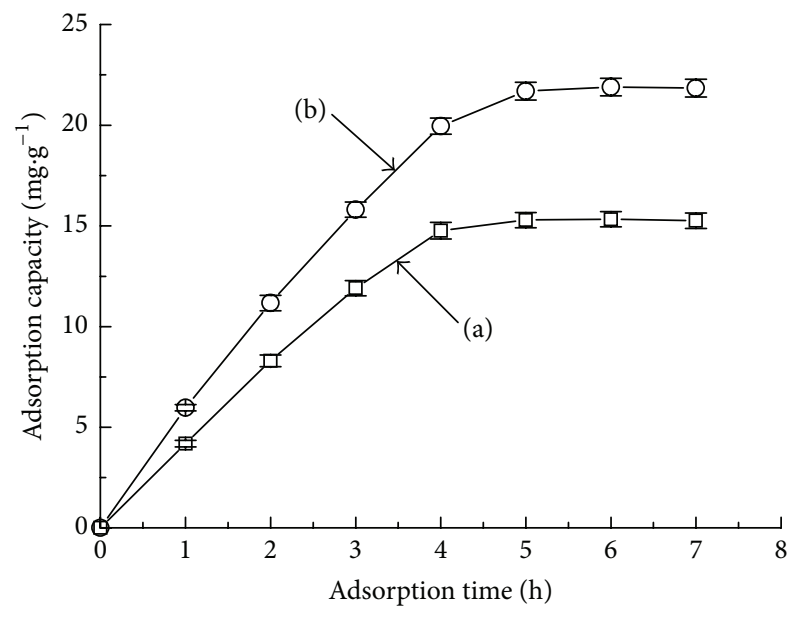

FIGURE 8: Adsorption curve of L-asparagine on DCLGG.

from the cross-linking or the oxidization. The cross-linking and the oxidization could obviously change the melting process of GG. The refraction of the polarized light on GG particles belonged to a single refraction. L-asparagine could be chemically bound by DCLGG. The results showed that dialdehyde cross-linked guar gum as a novel functional material would be well applied for many fields.

\section{Competing Interests}

The authors declare that they have no competing interests.

\section{Acknowledgments}

The authors are grateful to the individuals who have supported their research.

\section{References}

[1] D. N. Iqbal and E. A. Hussain, "Physiochemical and pharmaceutical properties of guar gum derivatives," Report and Opinion, vol. 2, no. 10, pp. 77-83, 2010.

[2] S. Pal, D. Mal, and R. P. Singh, "Synthesis and characterization of cationic guar gum: a high performance flocculating agent," Journal of Applied Polymer Science, vol. 105, no. 6, pp. 3240-3245, 2007.

[3] R. Fujioka, Y. Tanaka, and T. Yoshimura, "Synthesis and properties of superabsorbent hydrogels based on guar gum and succinic anhydride," Journal of Applied Polymer Science, vol. 114, no. 1, pp. 612-616, 2009.

[4] M. A. Shenoy and D. J. D'Melo, "Synthesis and characterization of acryloyloxy guar gum," Journal of Applied Polymer Science, vol. 117, no. 1, pp. 148-154, 2010.

[5] H. Gong, M. Liu, B. Zhang et al., "Synthesis of oxidized guar gum by dry method and its application in reactive dye printing," International Journal of Biological Macromolecules, vol. 49, no. 5, pp. 1083-1091, 2011.

[6] I. Gliko-Kabir, B. Yagen, A. Penhasi, and A. Rubinstein, "Low swelling, crosslinked guar and its potential use as colon-specific drug carrier," Pharmaceutical Research, vol. 15, no. 7, pp. 10191025, 1998.
[7] Y. Cheng, K. M. Brown, and R. K. Prud'homme, "Preparation and characterization of molecular weight fractions of guar galactomannans using acid and enzymatic hydrolysis," International Journal of Biological Macromolecules, vol. 31, no. 1-3, pp. 29-35, 2002.

[8] A. Tiwari and M. Prabaharan, "An amphiphilic nanocarrier based on guar gum-graft-poly( $\varepsilon$ - caprolactone) for potential drug-delivery applications," Journal of Biomaterials Science, Polymer Edition, vol. 21, no. 6-7, pp. 937-949, 2010.

[9] H.-S. Kim, D.-K. Hwang, B.-Y. Kim, and M.-Y. Baik, "Crosslinking of corn starch with phosphorus oxychloride under ultra high pressure," Food Chemistry, vol. 130, no. 4, pp. 977-980, 2012.

[10] P. J. Subrahmanyam, "Design and development of guar gum and borax crosslinked guar gum matrix tablets of theophylline for colon specific drug," Journal of Chemical and Pharmaceutical Research, vol. 4, no. 2, pp. 1052-1060, 2012.

[11] D. Ciolacu and M. Cazacu, "Synthesis of new hydrogels based on xanthan and cellulose allomorphs," Cellulose Chemistry and Technology, vol. 45, no. 3-4, pp. 163-169, 2011.

[12] K. Vikas, A. K. Tiwary, and K. Gurpreet, "Investigations on chitosan-carboxymethyl guar gum complexes interpolymer complexes for colon delivery of fluticasone," International Journal of Drug Delivery, vol. 2, pp. 242-250, 2010.

[13] F. Atyabi, S. Manoochehri, S. H. Moghadam, and R. Dinarvand, "Cross-linked starch microspheres: effect of cross-linking condition on the microsphere characteristics," Archives of Pharmacal Research, vol. 29, no. 12, pp. 1179-1186, 2006.

[14] R. Carmona-Garcia, M. M. Sanchez-Rivera, G. MéndezMontealvo, B. Garza-Montoya, and L. A. Bello-Pérez, "Effect of the cross-linked reagent type on some morphological, physicochemical and functional characteristics of banana starch (Musa paradisiaca)," Carbohydrate Polymers, vol. 76, no. 1, pp. 117-122, 2009.

[15] R. Tang, Y. Du, and L. Fan, "Dialdehyde starch-crosslinked chitosan films and their antimicrobial effects," Journal of Polymer Science, Part B: Polymer Physics, vol. 41, no. 9, pp. 993-997, 2003.

[16] L. Song, C. Cruz, S. R. Farrah, and R. H. Baney, "Novel antiviral activity of dialdehyde starch," Electronic Journal of Biotechnology, vol. 12, no. 2, pp. 1-5, 2009.

[17] A. A. Salisu, H. Musa, H. Abba, and A. A. Kogo, "Preparation and characterization of dialdehyde starch and its' cross-linking with copper (II) ion," Journal of Chemical and Pharmaceutical Research, vol. 5, no. 5, pp. 153-158, 2013.

[18] Y. Liu, G. Acharya, and C. H. Lee, "Effects of dialdehyde starch on calcification of collagen matrix," Journal of Biomedical Materials Research A, vol. 99, no. 3, pp. 485-492, 2011.

[19] R. Rosliza, A. Nora'Aini, and W. B. Wan Nik, "Study on the effect of vanillin on the corrosion inhibition of aluminum alloy," Journal of Applied Electrochemistry, vol. 40, no. 4, pp. 833-840, 2010.

[20] S. Rane and V. Kale, "Evaluation of modified guar gum as film coating material," International Journal of ChemTech Research, vol. 1, no. 2, pp. 180-182, 2009.

[21] S. Veelaert, M. Polling, and D. de Wit, "Structural and physicochemical changes of potato starch along periodate oxidation," Starch/Stärke, vol. 47, no. 7, pp. 263-268, 1995.

[22] U.-J. Kim, S. Kuga, M. Wada, T. Okano, and T. Kondo, "Periodate oxidation of crystalline cellulose," Biomacromolecules, vol. 1, no. 3, pp. 488-492, 2000. 
[23] T. Hongbo, L. Yanping, S. Min, and W. Xiguang, "Preparation and property of crosslinking guar gum," Polymer Journal, vol. 44, no. 3, pp. 211-216, 2012.

[24] A. J. Varma, S. P. Kokane, G. Pathak, and S. D. Pradhan, "Thermal behavior of galactomannan guar gum and its periodate oxidation products," Carbohydrate Polymers, vol. 32, no. 2, pp. 111-114, 1997.

[25] D. Y. Xu, Z. F. Liao, M. M. Zhao, and J. Y. Ren, "Preparation of dialdehyde konjac glucomamman," Advanced Materials Research, vol. 287-290, pp. 1700-1703, 2011.

[26] S.-D. Zhang, X.-L. Wang, Y.-R. Zhang, K.-K. Yang, and Y.-Z. Wang, "Preparation of a new dialdehyde starch derivative and investigation of its thermoplastic properties," Journal of Polymer Research, vol. 17, no. 3, pp. 439-446, 2010.

[27] T. Hongbo, S. Min, L. Yanping, and D. Siqing, "Preparation and properties of partially hydrolyzed cross-linked guar gum," Polymer Bulletin, vol. 70, no. 12, pp. 3331-3346, 2013.

[28] C. S. Raina, S. Singh, A. S. Bawa, and D. C. Saxena, "Some characteristics of acetylated, cross-linked and dual modified Indian rice starches," European Food Research and Technology, vol. 223, no. 4, pp. 561-570, 2006.

[29] D. Yu, S. Xiao, C. Tong, L. Chen, and X. Liu, "Dialdehyde starch nanoparticles: preparation and application in drug carrier," Chinese Science Bulletin, vol. 52, no. 21, pp. 2913-2918, 2007.

[30] R. Wongsagon, S. Shobsngob, and S. Varavinit, "Preparation and physicochemical properties of dialdehyde tapioca starch," Starch, vol. 57, no. 3-4, pp. 166-172, 2005.

[31] B. Beljkaš, J. Matić, I. Milovanović, P. Jovanov, A. Mišan, and L. Šarić, "Rapid method for determination of protein content in cereals and oilseeds: validation, measurement uncertainty and comparison with the Kjeldahl method," Accreditation and Quality Assurance, vol. 15, no. 10, pp. 555-561, 2010.

[32] A. V. Zhukov and A. G. Vereshchagin, "Quantitative determination of phosphorus in soybean lipids," Journal of Lipid Research, vol. 10, no. 6, pp. 711-713, 1969.

[33] J. Zeng, H. Gao, and G. Li, "Functional properties of wheat starch with different particle size distribution," Journal of the Science of Food and Agriculture, vol. 94, no. 1, pp. 57-62, 2014.

[34] S. Srichuwong, N. Isono, H. Jiang, T. Mishima, and M. Hisamatsu, "Freeze-thaw stability of starches from different botanical sources: correlation with structural features," Carbohydrate Polymers, vol. 87, no. 2, pp. 1275-1279, 2012.

[35] M. Majzoobi, M. Radi, A. Farahnaky, J. Jamalian, and T. Tongdang, "Physico-chemical properties of phosphoryl chloride cross-linked wheat starch," Iranian Polymer Journal, vol. 18, no. 6, pp. 491-499, 2009.

[36] S. Senanayake, A. Gunaratne, K. K. D. S. Ranaweera, and A. Bamunuarachchi, "Effect of heat moisture treatment conditions on swelling power and water soluble index of different cultivars of sweet potato (Ipomea batatas (L). Lam) starch," ISRN Agronomy, vol. 2013, Article ID 502457, 4 pages, 2013.

[37] K. O. Adebowale and O. S. Lawal, "Functional properties and retrogradation behaviour of native and chemically modified starch of mucuna bean (Mucuna pruriens)," Journal of the Science of Food and Agriculture, vol. 83, no. 15, pp. 1541-1546, 2003.

[38] S. Singh, C. S. Raina, A. S. Bawa, and D. C. Saxena, "Effect of heat-moisture treatment and acid modification on rheological, textural, and differential scanning calorimetry characteristics of sweetpotato starch," Journal of Food Science, vol. 70, no. 6, pp. E373-E378, 2005.
[39] Z.-P. Liang, Y.-Q. Feng, Z.-Y. Liang, S.-X. Meng, and X.-G. Liu, "Adsorption equilibrium and kinetics of urea nitrogen onto dialdehyde cellulose under catalysis of immobilized urease," Acta Chimica Sinica, vol. 64, no. 3, pp. 255-260, 2006.

[40] H. Tang, S. Gao, Y. Li, and S. Dong, "Modification mechanism of sesbania gum, and preparation, property, adsorption of dialdehyde cross-linked sesbania gum," Carbohydrate Polymers, vol. 149, pp. 151-162, 2016.

[41] D. Mudgil, S. Barak, and B. S. Khatkar, "X-ray diffraction, IR spectroscopy and thermal characterization of partially hydrolyzed guar gum," International Journal of Biological Macromolecules, vol. 50, no. 4, pp. 1035-1039, 2012.

[42] A. V. Singh, "A DSC study of some biomaterials relevant to pharmaceutical industry," Journal of Thermal Analysis and Calorimetry, vol. 112, no. 2, pp. 791-793, 2013.

[43] P. L. R. Cunha, R. R. Castro, F. A. C. Rocha, R. C. M. De Paula, and J. P. A. Feitosa, "Low viscosity hydrogel of guar gum: preparation and physicochemical characterization," International Journal of Biological Macromolecules, vol. 37, no. 1-2, pp. 99-104, 2005.

[44] T. Y. Bogracheva, Y. L. Wang, T. L. Wang, and C. L. Hedley, "Structural studies of starches with different water contents," Biopolymers, vol. 64, no. 5, pp. 268-281, 2002.

[45] D.-X. Yu, S.-Y. Xiao, C.-Y. Tong, L. Chen, and X.-M. Liu, "Dialdehyde starch nanoparticles: preparation and application in drug carrier," Chinese Science Bulletin, vol. 52, no. 21, pp. 29132918, 2007. 

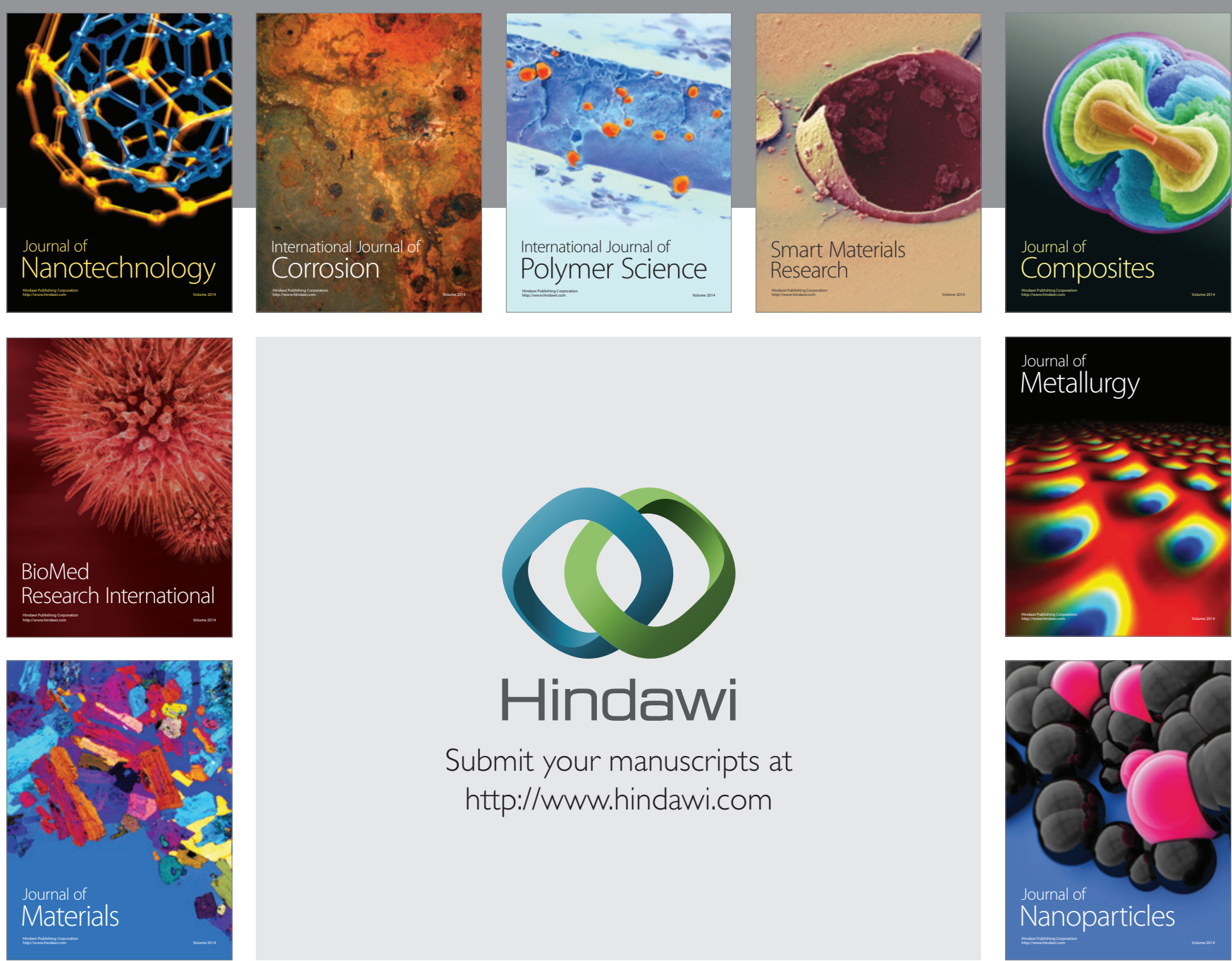

\section{Hindawi}

Submit your manuscripts at

http://www.hindawi.com

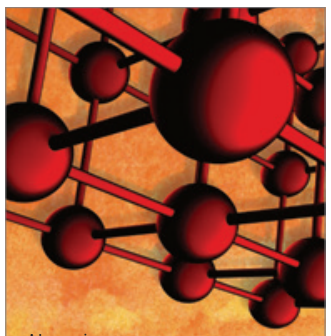

Materials Science and Engineering
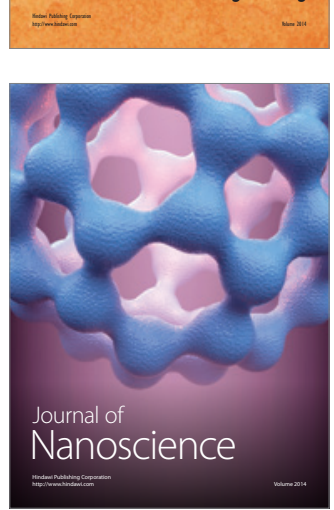
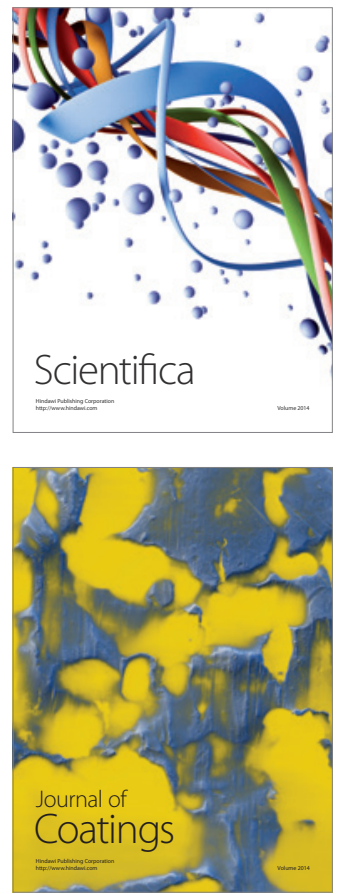
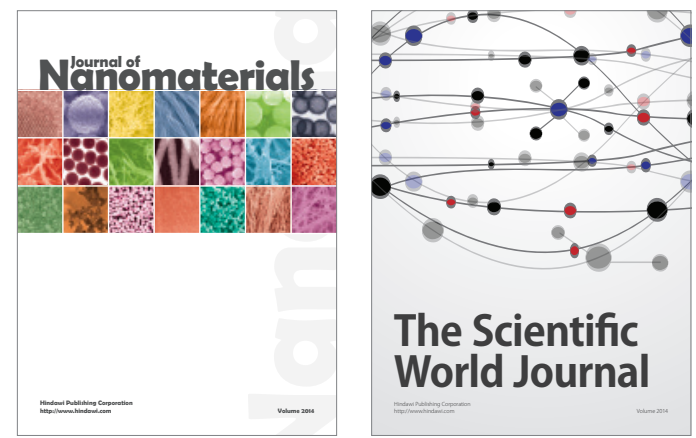

The Scientific World Journal
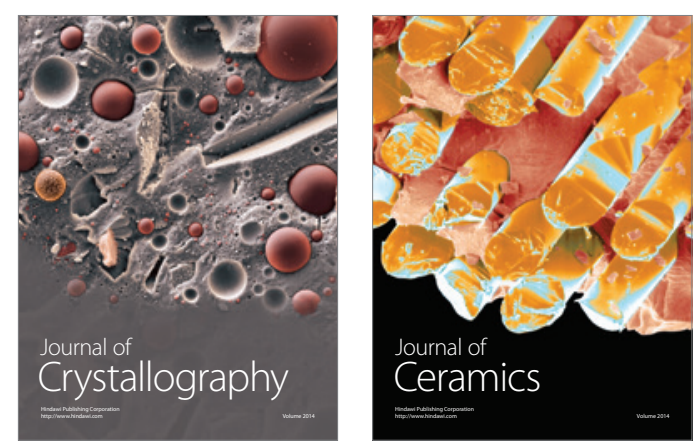
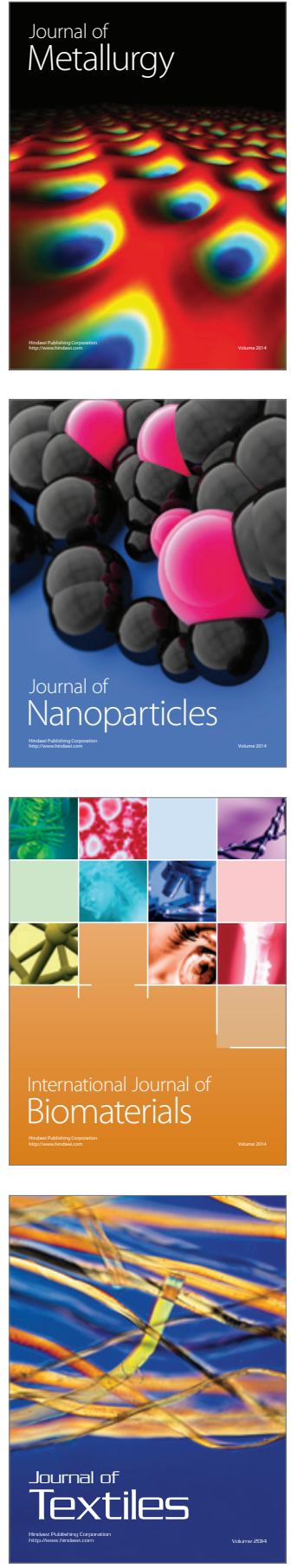